детей, страдающих аллергическими заболеваниями// Рос.педитр.журн.- М.2005.-№5.-c.26-29.

6. Жураева Ф.Р.//Паразитарные заболевания и новые подходы борьбы с гельминтозами//Молодой ученый - 2017. - 551. - С.109-111
7. Кабылбекова Э.У.//Распространение гельминтозов среди населения Жамбульской области.//Гигиена, эпидемиология и иммунология. Журн. -2010.-№4.-С.33-35.

\title{
THE PROBLEM OF NON-CORE AMBULANCE CALLS
}

\author{
Martynova Svetlana Aleksandrovna, \\ student of medical and preventive faculty, \\ Ural state medical University, \\ Vasyanina Anastasia Konstantinovna, \\ lecturer at the Department of public health and public health, \\ Ural state medical University, \\ Tall Natalia Alekseevna, \\ associate Professor of public health and health, doctor of medical Sciences, \\ Ural state medical University, \\ E-mail: svetma93@mail.ru
}

$\begin{array}{r}\text { ПРОБЛЕМА НЕПРОФИЛЬНЫХ ВЫЗОВОВ СКОРОЙ МЕДИЦИНСКОЙ ПОМОЩИ } \\ \hline \text { Мартынова Светлана Александровна, }\end{array}$ студент лечебно-профилактического факультета, ФГБОУ ВО Уральский государственный медицинский университет,

Васянина Анастасия Константиновна, преподаватель кафедры общественного здоровья и здравоохранения, ФГБОУ ВО Уральский государственный медииинский университет,

Рослая Наталья Алексеевна, доцент кафедры общественного здоровья и здравоохранения, доктор медицинских наук, ФГБОУ ВО Уральский государственный медицинский университет DOI: $10.31618 /$ ESU.2413-9335.2019.2.60.24-26

\section{ABSTRACT.}

The assessment of the structure and economic costs of non-core emergency medical calls of Chkalovsky district for 2017 and 2018 was carried out. Recommendations to reduce the number of non-core emergency calls on the example of Chkalovsky district.

\section{АННОТАЦИЯ.}

Была проведена оценка структуры и экономических затрат непрофильных вызовов скорой медицинской помощи Чкаловского района за 2017 и 2018 годы. Разработаны рекомендации по снижению количества непрофильных вызовов скорой медицинской помощи на примере Чкаловского района.

Key words: non-core calls, emergency medical care, structure of calls.

Ключевые слова: непрофильные вызовы, скорая медицинская помощь, структура вызовов.

Скорая медицинская помощь (СМП) - медицинская помощь, оказываемая гражданам при заболеваниях, несчастных случаях, травмах, отравлениях и других состояниях, требующих срочного медицинского вмешательства [5].

Среди проблем структурного реформирования отрасли здравоохранения важнейшее значение имеет совершенствование службы СМП [3]. Служба СМП выполняет несвойственные ей функции, подменяя обязанности амбулаторно-поликлинических учреждений по оказанию помощи на дому, что приводит к задержке оказания СМП, снижению своевременности и качества оказания медицинской помощи, перегруженности специализированных отделений стационара непрофильными больными $[1,4]$. Также крайне неэффективно используются специализированные врачебные бригады, простаивающие большую часть времени или выполняющие непрофильные вызовы [3]. Кроме того, выезд СМП на непрофильные вызовы приводит к значительным экономическим затратам, так как на 1 вызов СМП и за счет средств обязательного медицинского страхования выделяется в среднем 2224,6 рублей [2].

Проведено ретроспективное исследование. База исследования: подстанция скорой медицинской помощи №9, Чкаловский район, город Екатеринбург. Период наблюдений: с 1 января 2017 года по 31 октября 2018 года (численность населения Чкаловского района 265 113). Источники информации: первичная медицинская документация (истории болезни, рапорты). Объём выборки: 25062 вызовов, из них 14756 - непрофильные вызовы (10 мес. 2017 г.- 5245, 10 мес. 2018 г. - 5422).

Применялись методы: информационно-аналитический, статистический. Статистическая обработка результатов выполнена с использованием программы Excel, для оценки достоверности различий показателей применяли t-критерий Стьюдента $(\mathrm{p}<0,001)$.

К непрофильным вызовам СМП относятся: болевой синдром, не представляющий угрозу жизни; 
простудные заболевания, сопровождающиеся только подъёмом температуры, кроме детей до 3 лет; алкогольное опьянение лёгкой степени тяжести; вегето-сосудистый синдром; консультация СМП (назначение лекарственных средств); безрезультатные вызовы (улучшение состояния до приезда скорой помощи); вызов к больным с остаточными явлениями заболеваний нервной системы; неврозы; дисменорея; внезапные острые заболевания; состояния, не требующие срочного медицинского вмешательства; без явных признаков угрозы жизни, травмы любой этиологии, отравления, ранения, не сопровождающиеся кровотечением, представляющим угрозу жизни, или повреждением внутренних органов. В результате значительное количество выездов бригад скорой медицинской помощи к больным, нуждающимся в экстренном поддержании жизненных функций на места происшествий, выполняется несвоевременно [4, с. 270].

Результаты исследования показали, что за период январь - октябрь в 2017 году - 37,5\% и в 2018 г. 36,8\% вызовов приходится на непрофильные вызовы.

Структура непрофильных вызовов за исследуемый период не изменилась, при этом основными поводами стали вызовы из-за болевого синдрома, не представляющего угрозу жизни (более $23 \%$ ), на втором месте - вызовы из-за простудных заболеваний, сопровождающихся только подъёмом температуры, кроме детей до 3 лет (более 14\%), третье алкогольное опьянение лёгкой степени тяжести (более $12 \%$ ), четвёртое - травмы, отравления, не представляющие угрозу жизни (9,2\%).

При анализе структуры по времени года, выявлено, что наиболее часто во всех периодах встречаются - вызовы из-за болевого синдрома (боли из-за остеохондроза, обострений хронических заболеваний). Второе место изменяется в зависимости от сезона: в период с сентября по апрель - вызовы из-за простудных заболеваний, с мая по август - алкогольное опьянение лёгкой степени тяжести. Травмы и отравления, не представляющие угрозу жизни, становились поводами для вызова СМП в период с мая по август, занимая третье место.

В 2018 году в связи с увеличением числа вызовов и увеличения выделения средств на оказание СМП (в 2017 году на 1 вызов СМП в среднем выделялось 1819,5 рублей, в 2018 году - 2224,6 рублей).

Таблица 1. Экономические затраты в результате непрофильных вызовов за период январь - октябрь 2017 и 2018 г., рублей

\begin{tabular}{|l|c|c|c|}
\hline \multicolumn{1}{|c|}{ Непрофильные вызова } & $\begin{array}{l}2017 \text { год } \\
(10 \text { мес.) }\end{array}$ & $\begin{array}{c}2018 \text { год } \\
(10 \text { мес.) }\end{array}$ & Прирост 2018 г. (+/-) \\
\hline $\begin{array}{l}\text { Болевой синдром, не представляющий угрозу } \\
\text { жизни }\end{array}$ & 2299848 & 2838589,6 & $+538741,6$ \\
\hline $\begin{array}{l}\text { Простудные заболевания, сопровождающиеся } \\
\text { только подъёмом температуры, кроме детей до 3 лет }\end{array}$ & 1393737 & 1724065 & +330328 \\
\hline Алкогольное опьянение лёгкой степени тяжести & 1131729 & 1479359 & +347630 \\
\hline $\begin{array}{l}\text { Травмы, отравления, не представляющие угрозу } \\
\text { жизни }\end{array}$ & 846067,5 & 1185711,8 & $+339644,3$ \\
\hline Прочие & 3740892 & 4834055,8 & $+1093163,8$ \\
\hline Итого & 9412274 & 12061781,2 & $+2649507,2$ \\
\hline
\end{tabular}

Расход средств на непрофильные вызовы СМП увеличился на 28,1\% по сравнению с 2017 г. (табл. 1). Следует отметить, что фактически выполненный объём вызовов СМП соответствует запланированному объему вызовов СМП в соответствии с Программой государственных гарантий бесплатного оказания медицинской помощи

Укомплектованность среднего медицинского персонала СМП подстанции №9 - 80\%, увеличивается нагрузка на медицинский персонал, что приводит к снижению качества оказания медицинской помощи.

По результатам исследования разработаны следующие рекомендации по снижению количества вызовов скорой медицинской помощи:

1. Организация кабинета/отделения неотложной медицинской помощи в амбулаторно-поликлинических учреждениях в Чкаловском районе.

2. Разделение очереди для соблюдения сроков оказания медицинской помощи в неотложной форме в амбулаторных условиях в Чкаловском районе при обращении пациентов по поводу неотложных состояний.

3. Организация «Горячей линии» для консультаций пациентов и их родственников, передачи непрофильных вызовов СМП в отделение неотложной помощи.

4. Повышение профилактической направленности на базе МАУ ЦГБ №20:

- $\quad$ организация школ здоровья для пациентов с определёнными заболеваниями;

- проведение санитарно-просветительной работы среди прикрепленного населения о ведении здорового образа жизни, путем бесед с пациентами, памятки, плакаты;

- информирование о необходимости своевременного обследования, в том числе прохождении диспансеризации;

- формирования у пациентов приверженности к лечению. 


\section{Выводы}

1. Выполненный объём вызовов СМП соответствует запланированному объему вызовов СМП в соответствии с Программой государственных гарантий бесплатного оказания медицинской помощи.

2. В структуре вызовов СМП по профильности за исследуемый период более $35 \%$ приходится на непрофильные вызовы.

3. В зависимости от сезона структура непрофильных вызовов изменяется, так в период с января по апрель увеличивается доля простудных заболеваний, с мая по август увеличивается число вызовов по поводу алкогольного опьянения и травм, отравлений, не представляющих угрозу жизни.

4. Увеличиваются экономические затраты на вызовы СМП, в связи с увеличением числа вызовов и выделения средств на оказание СМП, при этом затраты на непрофильные вызовы составляют 45\%.

5. Укомплектованность среднего медицинского персонала СМП - 80\%, при этом увеличивается нагрузка на медицинский персонал.
Список литературы:

1. Приказ от 20 июня 2013 г. N 388н «Об утверждении порядка оказания скорой, в том числе скорой специализированной, медицинской помощи».

2. Постановление Правительства Российской Федерации от 19.12.2016 №1403 «О Программе государственных гарантий бесплатного оказания гражданам медицинской помощи на 2017 год и на плановый период 2018 и 2019 годы».

3. Приказ Минздрава России от 26.03.1999 г. №100 «О совершенствовании организации скорой медицинской помощи населению Российской Федерации».

4. Шумкин А.А. Определение потребности населения в анестезиолого-реанимационных видах скорой медицинской помощи. / А.А. Шумкин, Г.И. Чеченин. // Образовательные ресурсы и технологии. - 2016. - №1. - С. 269-276.

5. Федеральный закон от 21.11.2011 №323-Ф3 "Об основах охраны здоровья граждан в Российской Федерации".

\title{
ВЫСОКОИНТЕНСИВНАЯ ФОКУСИРОВАННАЯ УЛЬТРАЗВУКОВАЯ ТЕРАПИЯ В СОСТАВЕ НЕОАДЬЮВАНТНОГО ЛЕЧЕНИЯ У БОЛЬНЫХ РАКОМ МОЛОЧНОЙ ЖЕЛЕЗЫ: КЛИНИЧЕСКИЕ НАБЛЮДЕНИЯ.
}

\begin{abstract}
Хитрова Алла Николаевна
д.м.н., заведующая кабинетом ультразвуковой диагностики и терапии Московского научно-исследовательского онкологического института имени П.А. Гериена - филиал ФГБУ «Национальный медицинский исследовательский цеентр радиологии» Минздрава России (125284,Российская Федерация, Москва, 2-й Боткинский проезд, д. 3).

Москвичева Людмила Ивановна

врач-онколог кабинета ультразвуковой диагностики и терапии Московского научно-исследовательского онкологического института имени П.А. Герцена - филиал ФГБУ «Наичональный медииинский исследовательский иентр радиологии» Минздрава России (125284,Российская Федерация, Москва, 2-й Боткинский проезд, д. 3).

Суркова Виктория Сергеевна

врач-патологоанатом отделения патологической анатомии Московского научно-исследовательского онкологического института имени П.А. Гериена - филиал ФГБУ «Национальный медицинский исследовательский цеентр радиологии» Минздрава России (125284,Российская Федераичи, Москва, 2-й Боткинский проезд, д. 3). DOI: $10.31618 /$ ESU.2413-9335.2019.2.60.26-32

HIGH INTENSITY FOCUSED ULTRASOUND THERAPY AS PART OF NEOADJUVANT TREATMENT OF PATIENTS WITH BREAST CANCER: CLINICAL OBSERVATIONS.
\end{abstract}

\author{
Khitrova A. N., \\ Moskvicheva L. I., \\ Surkova $V . S$. \\ P. Hertsen Moscow Oncology Research Institute - Branch of the \\ National Medical Radiology Research Centre of the Ministry of Health of the Russian Federation \\ (2nd Botkinskiy proezd, Moscow, 125284, Russian Federation).
}

\section{АННОТАЦИЯ.}

Рак молочной железы - одно из наиболее социально значимых онкологических заболеваний у женщин во всем мире, характеризующееся огромным многообразием тактик и методов лечения.

Сегодня, в связи с активным развитием науки и техники в медицине, в клиническую практику внедряется значительное число современных высокотехнологичные методик местного воздействия на злокачественные новообразования различной локализации, применяемых с целью их деструкции, интенсификации системного лекарственного воздействия, увеличения числа положительных ответов опухоли на проводимое лечение. 